\title{
Characterization and Gas Sensing Properties of Copper-doped Tin Oxide Thin Films Deposited by Ultrasonic Spray Pyrolysis
}

\author{
Zhaoxia ZHAI, Jianqiao LIU *, Guohua JIN, Chuyao LUO, Qiuxuan JIANG, \\ Yuqing ZHAO
}

College of Information Science and Technology, Dalian Maritime University, Linghai Road 1, Ganjingzi District, Dalian 116026, Liaoning, China P.R.

cross $^{\text {ref }}$ http://dx.doi.org/10.5755/j01.ms.22.2.12917

Received 20 August 2015; accepted 09 December 2015

\begin{abstract}
Tin oxide-based thin films are deposited by ultrasonic spray pyrolysis technology, in which $\mathrm{Cu}$ addition is introduced to enhance the gas sensing performance by $\mathrm{H}_{2} \mathrm{~S}$ detection. The thin films are porous and comprise nano-sized crystallites. One of the $\mathrm{Cu}$-containing thin film sensors demonstrates a fast and significant response to $\mathrm{H}_{2} \mathrm{~S}$ gas. The values of power law exponent $n$ are calculated to discuss the sensitivity of the sensors, which is significantly promoted by $\mathrm{Cu}$ additive. The sensitivity of $\mathrm{Cu}$-doped $\mathrm{SnO}_{2}$ gas sensors is determined by two mechanisms. One is the normal gas sensing mechanism of $\mathrm{SnO}_{2}$ grains, and the other is the promoted mechanism caused by the transformation between $\mathrm{CuO}$ and $\mathrm{CuS}$ in the $\mathrm{H}_{2} \mathrm{~S}$ detection.

Keywords: tin oxide thin film, gas sensor, spray pyrolysis, hydrogen sulfide, sensitivity.
\end{abstract}

\section{INTRODUCTION}

Tin oxide $\left(\mathrm{SnO}_{2}\right)$ has become one of the best candidates for gas detection since its first appearance in commercial fabrication in 1962 [1]. This type of gas sensor succeeded in gas leakage warnings that prevented people from harm. Meanwhile, researchers were aware of the importance of $\mathrm{SnO}_{2}$ gas sensors, on which great effort has subsequently been exerted in both practical and theoretical aspects [2]. The known working mechanism of a $\mathrm{SnO}_{2}$ body comprises a joint function of receptor and transducer $[3,4]$. The $\mathrm{SnO}_{2}$ grain transduces the gas presence into a change in electrical resistance, controlled by the adsorbed oxygen on the grain surface. The sensor resistance decreases when exposed to reducing gases, while it increases if oxidizing gases are detected.

In recent decades, various devices have been fabricated in the forms of thick film [5], thin film [6] and nanostructures [7]. Response, sensitivity, and selectivity are deemed as the key parameters concerning gas sensors. One of the effective methods to improve sensor performance is the doping of foreign elements, which can substantially change the sensing properties and mechanism. Usually, $\mathrm{Cu}$ doping has been used to enhance sensor performance in $\mathrm{H}_{2} \mathrm{~S}$ detection. The sensitivity and selectivity subsequently benefited from the heterojunction between n-type $\mathrm{SnO}_{2}$ and p-type $\mathrm{CuO}$ [8]. However, there is still a lack of complete understanding about this type of sensor. For example, the sensitivity of $\mathrm{SnO}_{2}$ gas sensors for $\mathrm{H}_{2} \mathrm{~S}$ gas detection is enhanced by $\mathrm{Cu}$ additive [9], but the promotion mechanism of the sensitivity is not yet understood.

To reveal the effect of $\mathrm{Cu}$ additive on promoted sensitivity of $\mathrm{SnO}_{2}$ gas sensors, the present work reports

\footnotetext{
* Corresponding author. Tel.: +86-411-84729934; fax: +86-411-84729934. E-mail address: jqliu@dlmu.edu.cn (J. Liu)
}

the $\mathrm{SnO}_{2}$-based thin films fabricated using ultrasonic spray pyrolysis technology. $\mathrm{SnCl}_{2} \cdot 2 \mathrm{H}_{2} \mathrm{O}$ was used to prepare the precursor for deposition on alumina substrates. $\mathrm{CuCl}_{2} \cdot 2 \mathrm{H}_{2} \mathrm{O}$ was introduced to enhance the gas sensing performance in the $\mathrm{H}_{2} \mathrm{~S}$ detection. The thin film characteristics were discussed on the basis of the composition, morphology, crystallite size and electrical resistance in air. The gas sensing properties were tested by exposure to $\mathrm{H}_{2} \mathrm{~S}$ gas. The relationship between sensor response and gas concentration was concluded to calculate the values of the power law exponent of the $\mathrm{SnO}_{2}$-based thin films. The promotion mechanism of sensor sensitivity was discussed based on the effect of the $\mathrm{Cu}$ additive in the detection of $\mathrm{H}_{2} \mathrm{~S}$.

\section{EXPERIMENTAL DETAILS}

$\mathrm{SnO}_{2}$ thin films were deposited by ultrasonic spray pyrolysis technology on the alumina substrates with a pair of interdigital electrodes, the pattern of which has been previously described $[10,11] . \mathrm{SnCl}_{2} \cdot 2 \mathrm{H}_{2} \mathrm{O}$ was dissolved into absolute ethyl alcohol, in which the concentration of $\mathrm{Sn}^{2+}$ was kept to be $0.1 \mathrm{~mol} / \mathrm{L}$. The $\mathrm{Sn}$ solution was stirred in a magnetic stirring apparatus at $74{ }^{\circ} \mathrm{C}$ for 1 hour. $\mathrm{CuCl}_{2} \cdot 2 \mathrm{H}_{2} \mathrm{O}$ was dissolved according to identical methods to prepare a $\mathrm{Cu}$ solution, in which the $\mathrm{Cu}^{2+}$ concentration was $0.1 \mathrm{~mol} / \mathrm{L}$. The alumina substrates were placed in a tube chamber, which was heated to $350{ }^{\circ} \mathrm{C}$. A flow of $80 \mathrm{sccm} \mathrm{N}_{2}$ was used as the carrier gas to send the ultrasonicaly atomized spray of the $\mathrm{Sn}$ compound into the chamber, where the Sn composite was deposited on the substrates. The deposition time was 2 hours. The obtained sample was tagged as "FS(Pure)". The "FS(Sn-Cu)" sample was prepared by continuous deposition, which included Sn spray pyrolysis for 2 hours, and then $\mathrm{Cu}$ spray pyrolysis for 2 hours. Similarly, the "FS(Cu-Sn)" sample was acquired by a 2 hour $\mathrm{Sn}$ deposition after a 2 hour $\mathrm{Cu}$ 
deposition. The three types of samples were sintered at $550{ }^{\circ} \mathrm{C}$ for 2 hours.

X-ray diffraction (XRD) analysis was conducted by D/MAX-Ultima (Rigaku Corporation, Japan). The surface and profile morphology were observed by scanning electron microscopy (SEM; XL-30TMP, Philips, Netherlands). The resistance and gas sensing properties of the thin films were measured by a computer-controlled system, which has been previously described [11,12]. All measurements of thin film electrical properties were conducted at the operating temperature of $100{ }^{\circ} \mathrm{C}$ and under identical relative humidity of $40 \%$. The toxic $\mathrm{H}_{2} \mathrm{~S}$ was used as the target gas, the concentration of which was denoted by $C_{H 2 S}$. The film response $(S)$ was defined as the ratio of the film resistance in the air $\left(R_{a}\right)$ to film resistance in the target gas $\left(R_{g}\right)$, expressed as $S=R_{a} / R_{g}$. The power law exponent $n$ was calculated by $n=\mathrm{d} \lg S / \mathrm{d} \lg C_{H 2 S}$, which also defines the sensitivity of a gas sensor.

\section{RESULTS AND DISCUSSION}

Fig. 1 shows the XRD patterns of the FS(Pure), FS(Sn$\mathrm{Cu})$ and $\mathrm{FS}(\mathrm{Cu}-\mathrm{Sn})$ samples on the alumina substrates with $\mathrm{Ag}$ interdigital electrodes; the standard patterns of $\mathrm{SnO}_{2}$, $\mathrm{Al}_{2} \mathrm{O}_{3}$ and $\mathrm{Ag}$ are also illustrated. Three main $\mathrm{SnO}_{2}$ peaks of (110), (101) and (211) are observed in all samples. However, the two peaks (a) and (b) for metallic Sn are found in the $\mathrm{FS}(\mathrm{Sn}-\mathrm{Cu})$ sample, indicating that the $\mathrm{Cu}$ containing layer may prevent the oxidation of the $\mathrm{Sn}$ containing layer. Another peak (c) is detected in the $\mathrm{FS}(\mathrm{Cu}-\mathrm{Sn})$ sample for $\mathrm{CuO}-\mathrm{Al}_{2} \mathrm{O}_{3}$ compounds, which may result from the interaction between the $\mathrm{Cu}$-containing composite and the substrate.

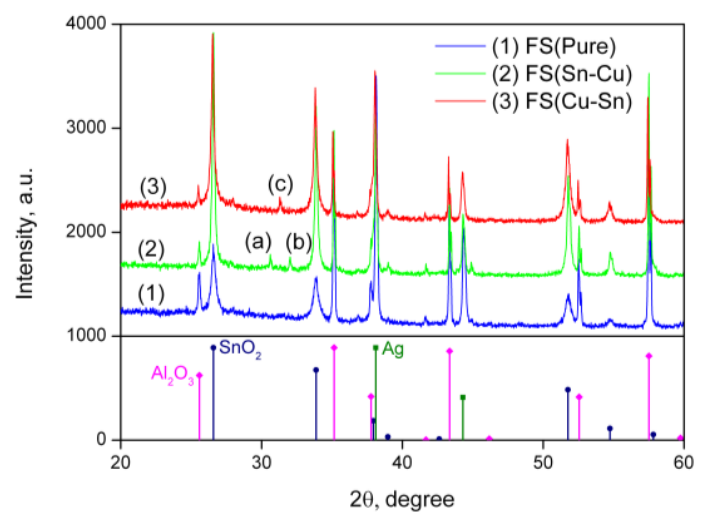

Fig. 1. XRD patterns of the FS(Pure), FS(Sn-Cu) and FS(Cu-Sn) thin film samples on the alumina substrates with $\mathrm{Ag}$ electrodes

Fig. 2 a, b show the morphology of the FS(Pure) thin film. The sample is porous and the grains appear spherical with varying sizes. Large grains with radii of several hundred nanometers are observed, indicating that secondary grain boundaries may exist inside such grains. Fig. $2 \mathrm{c}, \mathrm{d}$ show the profiles of $\mathrm{FS}(\mathrm{Sn}-\mathrm{Cu})$ and $\mathrm{FS}(\mathrm{Cu}-\mathrm{Sn})$ thin films on $\mathrm{Al}_{2} \mathrm{O}_{3}$ substrates, respectively. The porosity of the thin films is illustrated by the profile observation.

The characteristics of the three types of thin film samples are listed in Table 1 . The crystallite size of the FS(Pure) thin film is as small as $26.4 \mathrm{~nm}$, calculated from the XRD pattern according to Scherer's formula. Comparatively, $\mathrm{Cu}$-containing samples demonstrate larger
$\mathrm{SnO}_{2}$ crystallite size. The size of $\mathrm{SnO}_{2}$ crystallites in the $\mathrm{FS}(\mathrm{Sn}-\mathrm{Cu})$ thin film is $80.1 \mathrm{~nm}$ while that of the $\mathrm{FS}(\mathrm{Cu}-\mathrm{Sn})$ sample is $57.0 \mathrm{~nm}$. The typical film thickness of the present samples is measured to be approximately $150 \mathrm{~nm}$ from SEM profile observation. The deposition rate of $\mathrm{Cu}$ compound was found to be very low, so that the film thicknesses of three samples were almost the same. The electrical resistances of the thin films are measured in the air at $100{ }^{\circ} \mathrm{C}$. The $\mathrm{FS}$ (Pure) sample demonstrates the smallest resistance of $69.3 \mathrm{~K} \Omega$. The resistances of the thin films are significantly enhanced by the deposition of the $\mathrm{Cu}$ composition. This enhancement may be ascribed to the heterojunction between the n-type $\mathrm{SnO}_{2}$ and p-type $\mathrm{CuO}$ grains [8]. It is known that sensor properties have a grain size effect when the grain radius approaches the width of the depletion layer. This effect, which shows a negative relationship between grain size and gas sensing properties, has been discussed in previous literature $[12,13]$. For the present samples, $\mathrm{Cu}$-added thin films demonstrate greater grain sizes and enhanced sensor performances. This indicates that that $\mathrm{Cu}$ addition effectively improves the gas sensing properties in the detection of $\mathrm{H}_{2} \mathrm{~S}$ gas.

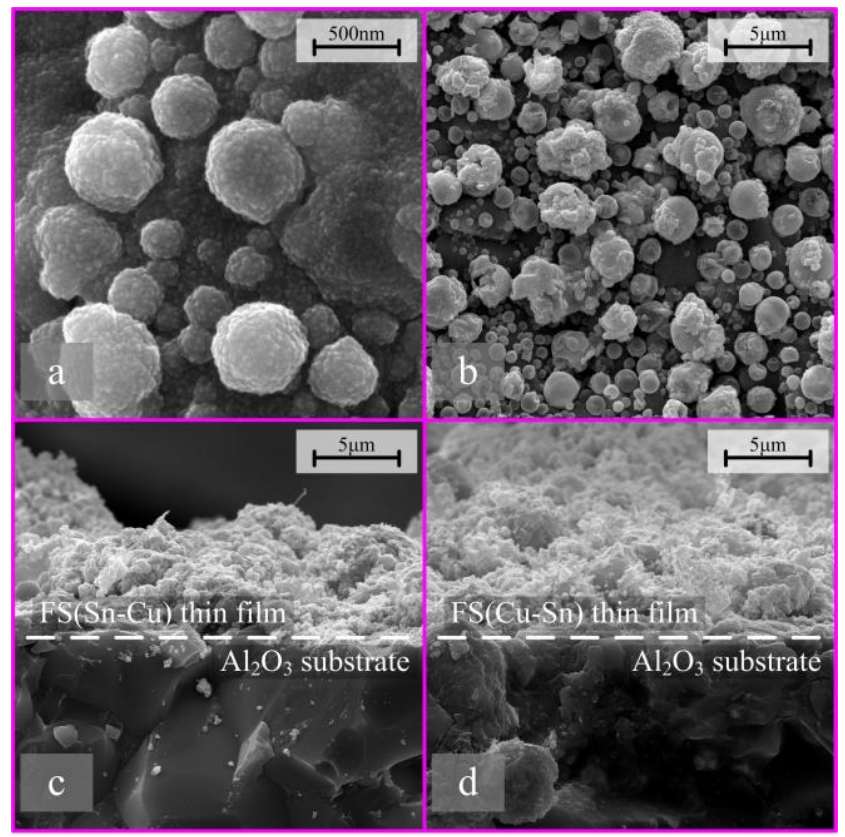

Fig. 2. Film morphology: $a, b-$ of the FS(Pure) thin film; $c$-in profiles of the $\mathrm{FS}(\mathrm{Sn}-\mathrm{Cu})$; d-FS(Cu-Sn) samples

Table 1. Characteristics of the FS(Pure), FS(Sn-Cu), and FS(CuSn) thin film samples at $100{ }^{\circ} \mathrm{C}$

\begin{tabular}{|c|c|c|}
\hline Sample & $\mathrm{SnO}_{2}$ crystallite size, $\mathrm{nm}$ & Resistance in air, $\mathrm{K} \Omega$ \\
\hline $\mathrm{FS}(\mathrm{Pure})$ & 26.4 & 69.3 \\
\hline $\mathrm{FS}(\mathrm{Sn}-\mathrm{Cu})$ & 80.1 & 481.7 \\
\hline $\mathrm{FS}(\mathrm{Cu}-\mathrm{Sn})$ & 57.0 & 692.6 \\
\hline
\end{tabular}

Fig. 3 shows the dynamic gas-sensing performances of thin films exposed to $\mathrm{H}_{2} \mathrm{~S}$ gas with the concentrations ranging from 13.7 to $95.9 \mathrm{ppm}$. The responses increase with gas concentration, the increase of which is indicated by the arrows in Fig. 3. The $\mathrm{FS}(\mathrm{Cu}-\mathrm{Sn})$ thin film demonstrates the best response of 13709 to $95.9 \mathrm{ppm}_{2} \mathrm{~S}$ gas, to which the FS(Pure) sample only gives a response of 149. It is very difficult to precisely explain why the $\mathrm{FS}(\mathrm{Cu}-$ $\mathrm{Sn})$ thin film responds more than the $\mathrm{FS}(\mathrm{Sn}-\mathrm{Cu})$ sample to $\mathrm{H}_{2} \mathrm{~S}$ detection. This phenomenon may be caused by several 
possible factors, such as film structure, number and size of p-n heterojunctions, and the possibility that $\mathrm{CuO}$ grains react with $\mathrm{H}_{2} \mathrm{~S}$ gas. Thus, further investigations are expected regarding those aspects.

It is known that the responses of semiconductor gas sensors follow a power law [14], the exponent of which can be obtained from the relationship between the sensor response and the gas concentration in the logarithmic coordinates. Fig. 4 shows the calculated $n$ values (sensitivity) of the prepared thin film sensors. For FS(Pure) thin film, $n$ is equal to 0.47 and approaching 0.5 when the adsorbed oxygen is dominated by the $\mathrm{O}^{-}$species [15]. In another aspect, much larger $n$ values greater than 1 are observed for the $\mathrm{Cu}$-containing samples. The same result was also observed in previous work [9]. However, the promotion mechanism of sensitivity caused by the $\mathrm{Cu}$ additive is still unclear.

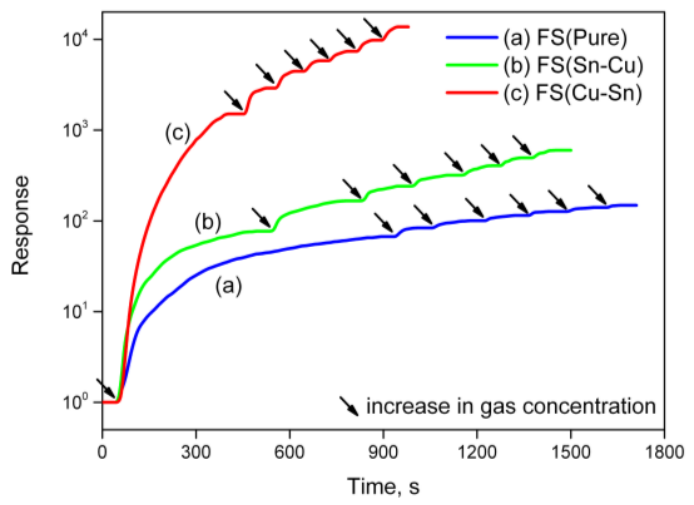

Fig. 3. Dynamic gas-sensing response to $\mathrm{H}_{2} \mathrm{~S}$ gas with the concentration from 13.7 to $95.9 \mathrm{ppm}$

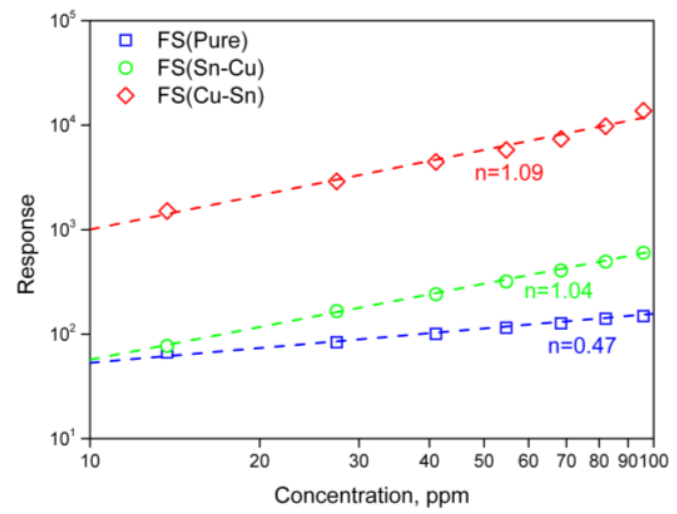

Fig. 4. The relationship between the thin film responses to the concentration of the $\mathrm{H}_{2} \mathrm{~S}$ gas and the calculated values of the power law exponent $(n)$

It has been proved that $\mathrm{Cu}$ additive in the $\mathrm{SnO}_{2}$ system occurs in the form of p-type $\mathrm{CuO}$ after sintering. $\mathrm{CuO}$ establishes the heterojunction and the potential barrier at the grain boundary connecting to n-type $\mathrm{SnO}_{2}$ grains. The exposure to $\mathrm{H}_{2} \mathrm{~S}$ gas causes the transformation of $\mathrm{CuO}$ to $\mathrm{CuS}$, as expressed in Eq. 1.

$$
\mathrm{H}_{2} \mathrm{~S}+\mathrm{CuO} \stackrel{\mathrm{k}_{1}}{\longrightarrow} \mathrm{CuS}+\mathrm{H}_{2} \mathrm{O} \text {. }
$$

The reverse transformation takes place when the $\mathrm{Cu}$ doped $\mathrm{SnO}_{2}$ gas sensor enters the aerial atmosphere, as expressed in Eq. 2.

$$
2 \mathrm{CuS}+3 \mathrm{O}_{2} \stackrel{\mathrm{k}_{2}}{\longrightarrow} 2 \mathrm{CuO}+2 \mathrm{SO}_{2} \text {. }
$$

Several presumptions are proposed for discussion as follows: (1) the nominal concentration of $\mathrm{CuO}$ and $\mathrm{CuS}$ grains in the $\mathrm{SnO}_{2}$ thin films are indicated by [CuO] and [CuS], which indicates the number of $\mathrm{CuO}$ or $\mathrm{CuS}$ grains involved per unit volume of the thin film; (2) $\mathrm{CuO}$ grains can adsorb $m \mathrm{H}_{2} \mathrm{~S}$ gas molecules during gas detection when $\mathrm{CuO}$ converts to $\mathrm{CuS}$; (3) each $\mathrm{CuS}$ resultant provides $t$ carriers into the nearby depletion layer of the $\mathrm{SnO}_{2}$ grain for conductance, $[\mathrm{CuS}]=t\left[\mathrm{e}^{-}\right]$. Therefore, the following equation detailing the accumulation of $\mathrm{CuS}$ can be obtained.

$$
\frac{d[\mathrm{CuS}]}{d t}=k_{1} C_{\mathrm{H}_{2} \mathrm{~S}}^{m}[\mathrm{CuO}]-k_{2}\left(t\left[e^{-}\right]\right)^{2} P_{O_{2}}^{3} .
$$

At the steady state, $\mathrm{d}[\mathrm{CuS}] / \mathrm{d} t=0$. Thus, $\left[\mathrm{e}^{-}\right]$can be formulated as Eq. 4.

$\left[e^{-}\right]=\left(\frac{k_{1}[\mathrm{CuO}]}{k_{2} t^{2} P_{O_{2}}^{3}}\right)^{1 / 2} C_{\mathrm{H}_{2} \mathrm{~S}}^{m / 2}$.

It is known that the response of thin films is proportional to $\left[\mathrm{e}^{-}\right]$so that $S$ is proportional to $C_{H 2 S}{ }^{m / 2}$. Hence, the power law exponent $n$ is equal to $m / 2$ for $\mathrm{Cu}$ added $\mathrm{SnO}_{2}$ gas sensors. The specific value of $m$ is significant, but it cannot be known at this time. According to the definition, its value is likely to be much larger than 2, which leads to a large value of $n$; this could be the sensitivity promotion mechanism of the $\mathrm{Cu}$-added $\mathrm{SnO}_{2}$ elements. However, from experimental observation, the value of $n$ remains around 1 . This implies that the sensitivity of $\mathrm{Cu}$-doped $\mathrm{SnO}_{2}$ gas sensors may be controlled by two mechanisms: one is the normal gas sensing mechanism of pure $\mathrm{SnO}_{2}$ grains, while the other is the promoted mechanism caused by the transformation between $\mathrm{CuO}$ and $\mathrm{CuS}$ in $\mathrm{H}_{2} \mathrm{~S}$ detection. Once the specific value of $m$ is determined, the contribution of each mechanism can be separated.

\section{CONCLUSIONS}

$\mathrm{SnO}_{2}$-based thin film gas sensors were fabricated on alumina substrate by ultrasonic spray pyrolysis technology. Three types of thin films were prepared and characterized by XRD, SEM, and electrical properties. The thin film samples were porous and demonstrated crystallite sizes of 26.4-80.1 nm. The gas sensing performances of the thin films were tested by exposure to toxic $\mathrm{H}_{2} \mathrm{~S}$ gas, to which the $\mathrm{FS}(\mathrm{Cu}-\mathrm{Sn})$ sample showed a fast and high response of 13709 at $100{ }^{\circ} \mathrm{C}$. The power law exponent $n$ was calculated for each sample. The value of $n$ for FS(Pure) sample was 0.47 while the values for the $\mathrm{Cu}$-containing samples were greater than 1 . The promotion mechanism of sensor sensitivity was discussed based on the transformation between $\mathrm{CuO}$ and $\mathrm{CuS}$ in $\mathrm{H}_{2} \mathrm{~S}$ detection by $\mathrm{Cu}$-doped $\mathrm{SnO}_{2}$ gas sensors. The sensitivity of such devices is controlled by two mechanisms, one of which is the normal gassensing mechanism of $\mathrm{SnO}_{2}$ grains and the other of which is the $\mathrm{Cu}$-promoted mechanism in the $\mathrm{SnO}_{2}$ element for $\mathrm{H}_{2} \mathrm{~S}$ detection.

\section{Acknowledgments}

This work was financially supported by the Fundamental Research Funds for the Central Universities (Grant No. 3132015035) and the Liaoning Natural Science Foundation (Grant No. 2015020019). 


\section{REFERENCES}

1. Seiyama, T., Kato, A., Fujiishi, K., Nagatani, M. A New Detector for Gaseous Components Using Semiconductive Thin Films Analytical Chemistry 34 (11) 1962: pp. $1502-1503$.

2. Sakai, G., Matsunaga, N., Shimanoe, K., Yamazoe, N. Theory of Gas-Diffusion Controlled Sensitivity for Thin Film Semiconductor Gas Sensor Sensors and Actuators B: Chemical 80 (2) 2001: pp. 125-131.

3. Yamazoe, N., Shimanoe, K. Basic Approach to the Transducer Function of Oxide Semiconductor Gas Sensors Sensors and Actuators B: Chemical 160 (1) 2011: pp. 1352-1362.

4. Yamazoe, N., Shimanoe, K. New Perspectives of Gas Sensor Technology Sensors and Actuators B: Chemical 138 (1) 2009: pp. 100-107.

5. Liu, H., Wu, S., Gong, S., Zhao, J., Liu, J., Zhou, D. Nanocrystalline $\mathrm{In}_{2} \mathrm{O}_{3}-\mathrm{SnO}_{2}$ Thick Films for LowTemperature Hydrogen Sulfide Detection Ceramics International 37 (6) 2011: pp. 1889-1894. http://dx.doi.org/10.1016/j.ceramint.2011.02.005

6. Liu, J., Gong, S., Xia, J., Quan, L., Liu, H., Zhou, D. The Sensor Response of Tin Oxide Thin Films to Different Gas Concentration and the Modification of the Gas Diffusion Theory Sensors and Actuators B: Chemical 138 (1) 2009: pp. 289-295.

7. Miller, D.R., Akbar, S.A., Morris, P.A. Nanoscale Metal Oxide-Based Heterojunctions for Gas Sensing: A Review Sensors and Actuators B: Chemical 2014: pp. 250-272. http://dx.doi.org/10.1016/j.snb.2014.07.074

8. Tamaki, J., Maekawa, T., Miura, N., Yamazoe, N. Cuo$\mathrm{SnO}_{2}$ Element for Highly Sensitive and Selective
Detection of $\mathrm{H}_{2} \mathrm{~S}$ Sensors and Actuators B: Chemical 9 (3) 1992: pp. 197-203.

http://dx.doi.org/10.1016/0925-4005(92)80216-K

9. Tamaki, J., Shimanoe, K., Yamada, Y., Yamamoto, Y., Miura, N., Yamazoe, N. Dilute Hydrogen Sulfide Sensing Properties of $\mathrm{CuO}-\mathrm{SnO}_{2}$ Thin Film Prepared by LowPressure Evaporation Method Sensors and Actuators B: Chemical 49 (1-2) 1998: pp. 121-125.

10. Liu, J., Gong, S., Quan, L., Deng, Z., Liu, H., Zhou, D. Influences of Cooling Rate on Gas Sensitive Tin Oxide Thin Films and a Model of Gradient Distributed Oxygen Vacancies in $\mathrm{SnO}_{2}$ Crystallites Sensors and Actuators B: Chemical 145 (2) 2010: pp. 657-666. http://dx.doi.org/10.1016/j.snb.2010.01.015

11. Liu, J., Gong, S., Fu, Q., Wang, Y., Quan, L., Deng, Z., Chen, B., Zhou, D. Time-Dependent Oxygen Vacancy Distribution and Gas Sensing Characteristics of Tin Oxide Gas Sensitive Thin Films Sensors and Actuators B: Chemical 150 (1) 2010: pp. 330-338.

12. Liu, J., Jin, G., Zhai, Z., Monica, F.F., Liu, X. Numeral Description of Grain Size Effects of Tin Oxide Gas-Sensitive Elements and Evaluation of Depletion Layer Width Electronic Materials Letters 11 (3) 2015: pp. 457-465.

13. Liu, J., Zhai, Z., Jin, G., Li, Y., Monica, F.F., Liu, X. Simulation of the Grain Size Effect in Gas-Sensitive $\mathrm{SnO}_{2}$ Thin Films Using the Oxygen Vacancy Gradient Distribution Model Electronic Materials Letters 11 (1) 2015: pp. 34-40.

14. Yamazoe, N., Shimanoe, K. Theory of Power Laws for Semiconductor Gas Sensors Sensors and Actuators B: Chemical 128 (2) 2008: pp. 566-573.

15. Morrison, S.R. Mechanism of Semiconductor Gas Sensor Operation Sensors and Actuators $11(3)$ 1987: pp. $283-287$. 